\title{
Do mato ao palco: a construção da nação em Moçambique através da música
}

From the bush to the stage: nation building in Mozambique through music

\section{Sara Morais}

\section{(2) OpenEdition}

12 Journals

Edição electrónica

URL: https://journals.openedition.org/aa/9483

DOI: $10.4000 /$ aa. 9483

ISSN: 2357-738X

Editora

Programa de Pós-Graduação em Antropologia Social (UnB)

\section{Edição impressa}

Paginação: 208-227

ISSN: 0102-4302

\section{Refêrencia eletrónica}

Sara Morais, «Do mato ao palco: a construção da nação em Moçambique através da música», Anuário Antropológico [Online], v.47 n. 1 | 2022, posto online no dia 31 janeiro 2022, consultado o 22 julho 2022. URL: http://journals.openedition.org/aa/9483 ; DOI: https://doi.org/10.4000/aa.9483

\section{(c) (i) (9)}

Creative Commons - Atribuição-NãoComercial-SemDerivações 4.0 Internacional - CC BY-NC-ND 4.0 https://creativecommons.org/licenses/by-nc-nd/4.0/ 


\section{Anuário Antropológico}

v.47 n.1 | 2022

2022/v.47 n.1

Do mato ao palco: a construção musical da nação em Moçambique

From the bush to the stage: the musical construction of the nation in Mozambique

\section{Sara Morais}

\section{OpenEdition \\ Journals}

\section{Edição electrônica}

URL: http://journals.openedition.org/aa/9483

DOI: $10.4000 / a a .9483$

ISSN: 2357-738X

\section{Editora}

Programa de Pós-Graduação em Antropologia Social (UnB)

\section{Referência eletrônica}

Sara Morais, «Do mato ao palco: a construção musical da nação em Moçambique», Anuário

Antropológico [Online], v.47 n.1| 2022. URL: http://journals.openedition.org/aa/9483; DOI: https://doi.

org/10.4000/aa.9483

\section{(c) (i)}

Anuário Antropológico is licensed under a Creative Commons. Atribuição-SemDerivações-SemDerivados CC BY-NC-ND 


\title{
Do mato ao palco: a construção musical da nação em Moçambique
}

\author{
From the bush to the stage: the musical construction of the nation in Mozambique
}

DOI: https://doi.org/10.4000/aa.9483

\author{
Sara Morais \\ Universidade de Brasília - Brasil \\ Doutora em Antropologia Social pelo Departamento de Antropologia da Universidade de Brasília, onde é \\ atualmente pesquisadora colaboradora plena. Desde 2013 é técnica em antropologia do IPHAN/Departa- \\ mento de Patrimônio Imaterial. Suas pesquisas atuais têm como foco de análise o processo de patrimonia- \\ lização das timbila em Moçambique.
}

Este artigo discute a realização do I Festival Nacional da Canção e Música Tradicional (1980-1981) em Moçambique e o reputa como a iniciativa de maior destaque promovida pelo governo da Frelimo (Frente de Libertação de Moçambique) no seu projeto de construção nacional durante os primeiros anos após a independência do país no campo musical. Após a descrição e análise da programação deste Festival, recupero o debate acalorado promovido pela grande imprensa da época sobre certos dilemas envolvidos na sua organização e na classificação "música tradicional”. Nos palcos construídos na capital, Maputo, pessoas oriundas das diversas províncias do país passaram a ser conhecidas como artistas, denominação adquirida ao serem instadas a abandonar suas vinculações "tribais". Argumento que, a despeito das várias transformações políticas pelas quais o país passou nas últimas décadas, especialmente após o fim da guerra civil (1976/1977-1992), o Festival Nacional da Canção e Música Tradicional permaneceu como paradigma. A partir dos anos 2000, a realização de festivais culturais continua sendo uma estratégia central de construção da unidade nacional.

Moçambique; música tradicional; nação; festivais de cultura; África.
This article discusses the first National Festival of Traditional Music and Song (1980-1981) in Mozambique. It regards this festival as the most important initiative promoted by the Frelimo government (Frente de Libertação de Moçambique) as part of its nation-building project during the first years after the country's independence in the musical field. After describing and analyzing the programming of this festival, I will recover the heated debate promoted by the mainstream press about dilemmas involved in its organization and about the classification of "traditional music". On the stages built in the capital, Maputo, people from the various provinces of the country came to be known as artists, a denomination acquired when they were urged to abandon their "tribal" ties. I argue that, despite the various political transformations that the country has undergone in recent decades, especially after the end of the civil war (1976/1977-1992), the National Festival of Song and Traditional Music has remained a paradigm. From the 2000s onwards, the holding of cultural festivals continues to be a central strategy for building national unity. 
Numa imponente cerimônia, plena de movimento, ritmo, cor e alegria, o Presidente Samora Machel presidiu na tarde de ontem, em Maputo, à abertura da fase final do Primeiro Festival Nacional de Canção e Música Tradicional, acontecimento que reuniu milhares de pessoas. Na ocasião, o Marechal Samora Machel saudou as centenas de artistas representativos das 10 províncias do nosso País, sublinhando que através da dança e dos músicos eles mostram "o nosso passado, segredo da força que quebrou as algemas, o tribalismo, o regionalismo e o racismo" e mostram "o internacionalismo, a solidariedade e, sobretudo, a unidade do Povo moçambicano".

Esse trecho de reportagem do Jornal Notícias estampava a capa da edição do dia 28 de dezembro de 1980, quando estreou o grande acontecimento que se tornou a menina dos olhos da Frelimo (Frente de Libertação de Moçambique) ${ }^{1}$ em sua pauta de assuntos culturais nos primeiros anos após conquistada a independência do país: o Festival Nacional da Canção e Música Tradicional. O evento se estendeu até o dia 3 de janeiro de 1981, com apresentações diárias dos cerca de 400 músicos "tradicionais" que foram previamente selecionados em todas as dez províncias daquele território no Pavilhão do estádio Maxaquene e em palcos espalhados em escolas e fábricas de Maputo, a capital. Sua realização foi o ponto áureo da "política cultural"2 da Frelimo no pós-independência, a atividade de maior envergadura dentre aquelas que vinham sendo concretizadas no âmbito das diretrizes estipuladas no seu III Congresso, ${ }^{3}$ tais como: a Reunião Nacional de Cultura (1977), o I Festival Nacional de Dança Popular (1978), a Ofensiva Cultural das Classes Trabalhadoras e a Campanha Nacional de Preservação e Valorização Cultural (1978-1982). O Festival Nacional da Canção e Música Tradicional (doravante o Festival) foi arquitetado como uma atividade resultante dessa Campanha. ${ }^{4}$

Meu objetivo neste artigo é discutir o lugar ocupado por esse Festival, ocorrido no final de 1980 e início de 1981, no projeto de construção da nação em Moçambique. ${ }^{5}$ Embora minha análise se concentre num evento realizado em momento singular da história pós-colonial desse país africano, é possível afirmar que seu modelo de organização voltou a fazer parte da agenda política nos anos 2000 quando eventos dessa natureza puderam acontecer, após o duro período de dezesseis anos de guerra civil -, perpetuando-se até os dias atuais. Os festivais se tornaram a principal linha de atuação do governo moçambicano contemporâneo no campo cultural, tendo sido incorporados a discursos políticos distintos, mas muitas vezes complementares, no decorrer de suas realizações. Apesar das novas proposições e da elaboração de uma política cultural estruturada sob o alicerce da sociedade democrática multipartidária que supostamente teria surgido no pós-guerra, a realização de festivais persistiu como a melhor estratégia de busca pela construção da unidade nacional. Trata-se aqui, portanto, de um foco de reflexão sobre a via institucional de uma versão do projeto de nação proposto naquele período, a qual se alterou nos anos subsequentes, principalmente após a Conferência Nacional de Cultura, ocorrida em 1993 (Morais 2020).
1 A bibliografia que trata sobre a Frente de Libertação de Moçambique (seu surgimento, papel na luta pela independência, transformação da Frente em Partido, guerra contra a Renamo, etc.) é bastante extensa. Cf. particularmente Darch (2018), Cabaço (2009), Newitt (1995), Kruks (1987), Isaacman e Isaacman (1983).

2 Utilizo o termo entre aspas porque nesse período as atividades realizadas ainda não são consideradas como um conjunto articulado de iniciativas previstas em leis, em resoluções, ou outros instrumentos institucionalizados em todos os níveis da administração pública.

3 A partir do III Congresso, a Frente de Libertação se torna partido de vanguarda da revolução socialista, ou o "Partido de vanguarda da aliança operário-camponesa" (Tempo, 1977, 44), alinhando-se à "Revolução Proletária Mundial”. Segundo Geffray (1991, 16), "pouco a pouco foram-se definindo no discurso do poder os contornos estranhos de um país fictício: dizia-se que a autoridade da Frelimo ter-lhe-ia sido delegada por uma 'aliança operário-camponesa', para que exercesse, em seu nome, a ditadura sobre os seus inimigos, os inimigos do povo. O 'marxismo' constituiu o corpus conceptual que permitia a invenção do país imaginário e a garantia dogmática da coerência interna da ficção que alimentava o projecto nacionalista de poder".

4 A organização do evento ficou a cargo do Gabinete Central de Organização do Festival da Canção e Música Tradicional, ligado à então Direção Nacional de Cultura Serviço Nacional de Museus e Antiguidades.

5 Para tanto, utilizo como fontes de análise reportagens do Jornal Notícias e da Revista Tempo. Ambos, cuja existência é anterior à independência, alinharam-se às diretrizes da Frelimo voltadas à 

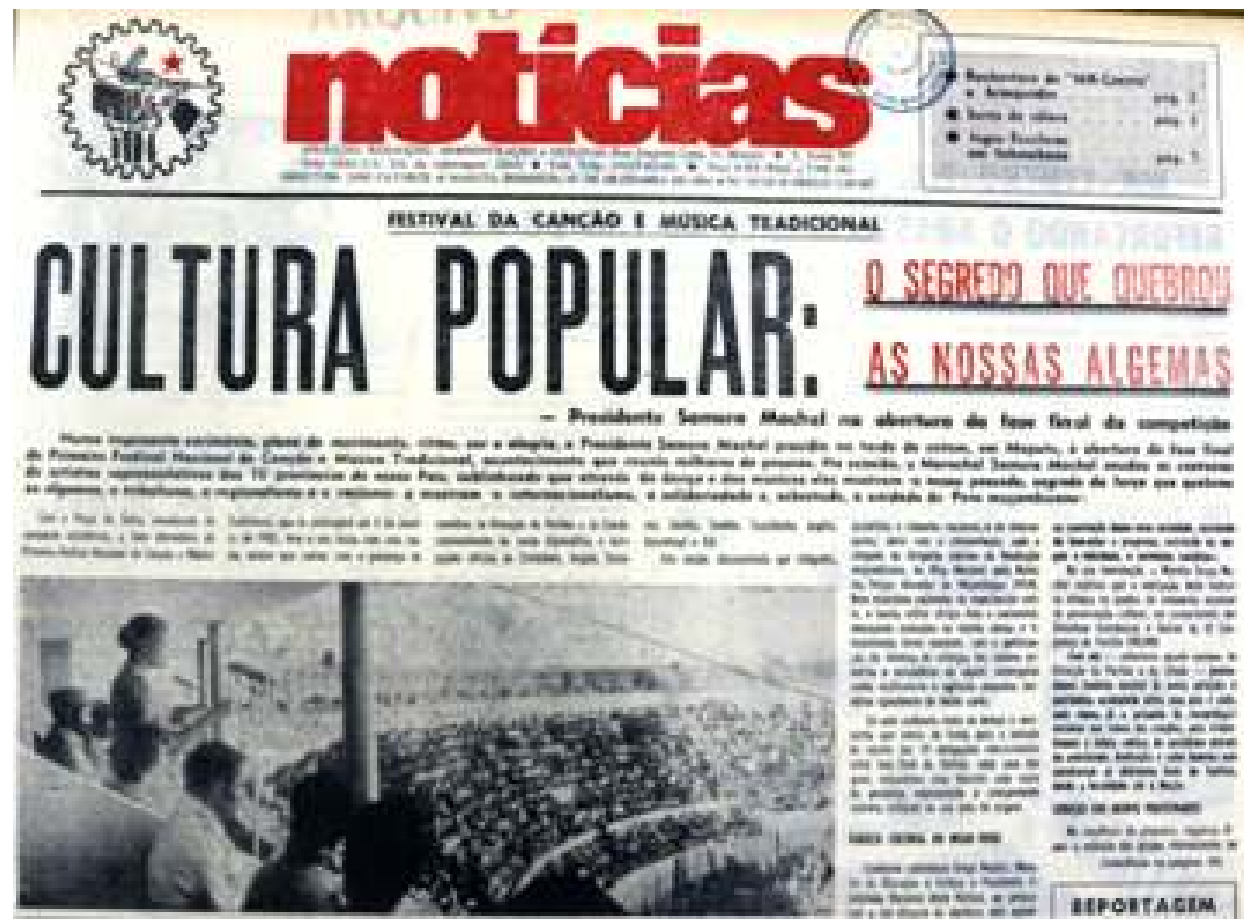

Mais especificamente, discutirei como a realização do Festival utilizou os palcos montados no estádio da Machava, no pavilhão do Maxaquene e em outros locais na cidade de Maputo para colocar em destaque diversas manifestações musicais do país. Festivais de cultura foram e continuam sendo realizados em diversas partes do continente africano no contexto de pós-independências. Minhas análises se amparam em recentes abordagens sobre o tema (Murphy 2016, de Jong 2016, Apter 2005, 2016), por considerarem que a realização desses festivais continua a desempenhar um papel central na construção de identidades local, regional e nacional (Andrieu 2013).

Transportados do mato para o palco, os representantes das manifestações exibidas no Festival da Canção e Música Tradicional passaram a ser denominados artistas. Argumento que uma das principais estratégias da Frelimo à época direcionou-se justamente ao disciplinamento da população através de atividades no campo cultural: a mobilização de pessoas vinculadas a vários tipos de gêneros de produção artística em todo o país, o levantamento de informações de aspectos diversos sobre os grupos sociais do território nacional, a produção de eventos de propaganda oficial do governo, entre outras.

O que se denominou como "política cultural" nos cinco primeiros anos do governo da Frelimo só pode ser compreendido a partir do ideal mais amplo de construção de uma sociedade fundada pelo poder popular, pela luta de classes e pelas estratégias de governo utilizadas para tal empreendimento. A despeito das mudanças transcorridas desde então no país em termos de orientação política, econômica e ideológica, as principais linhas de atuação, organização e concepção de atividades no campo da cultura, como os festivais, assim como as definições e noções de termos como "música tradicional" e "patrimônio cultural" mantiveram-se mais ou menos inalteradas no decorrer dos anos. Os festivais funcionaram e continuam a funcionar como palco não somente para a apresentação de uma
FIGURA 1: Notícias, 28 de dezembro de 1980.

comunicação de massas e à divulgação dos seus feitos, com objetivo de conscientização do povo em relação aos ideais revolucionários de construção da nova sociedade que se queria erigir com a saída dos portugueses em 1975. Os dados utilizados neste artigo foram produzidos por meio da minha pesquisa de doutorado realizada em Moçambique durante todo o ano de 2018, que combinou pesquisa de campo etnográfica e de arquivo. Especificamente no caso deste artigo, o material selecionado foi consultado no Arquivo Histórico de Moçambique, no Arpac (Instituto de Investigação Sociocultural, antigo Arquivo do Patrimônio Cultural) e na biblioteca do INAC (Instituto Nacional de Audiovisual e Cinema). 
amostra dos principais gêneros musicais existentes no país, mas sobretudo como plataforma para efetivação de fins políticos. Se considerarmos que o Estado nascente em Moçambique, como argumenta Newitt (1995), confunde-se em muitos momentos com a própria Frelimo, a organização de eventos dessa dimensão, que envolvem representantes de todo o país (ou seja, representantes de vários grupos sociais espalhados pelo país), foram a motivação perfeita para a abordagem política da época.

A abordagem sobre o Festival, nesse contexto, reúne uma série de elementos que nos permite visualizar, a partir de uma perspectiva pouco usual, o panorama das iniciativas da Frelimo no pós-independência voltadas à construção da nação. Ou seja, ao invés de simplesmente afirmar que "a cultura" desempenhou um papel fundamental nas concepções de revolução socialista e construção do homem novo, procuro entender, a partir das fontes produzidas naquela época, os sentidos mais amplos que os temas mobilizados pelo debate no campo cultural e musical suscitavam em termos de sua associação com a nação.

À nação atribuo dois sentidos gerais: um de caráter mais oficial, atrelado às delimitações, estratégias e escolhas políticas do Estado soberano num determinado território, aproximando-me da abordagem de Benedict Anderson (1989), e outro de caráter menos evidente, relativo ao modo como timbileiros ${ }^{6}$ e técnicos da área da cultura em Moçambique vivem na prática as nuances das políticas desse Estado. Minhas análises sobre o tema se amparam na proposta de Trajano Filho $(1993,8)$ de lidar com a questão da nacionalidade "pela via da identidade social", esta se referindo "ao modo pelo qual pessoas e grupos pertencem a uma totalidade construída enquanto representação". Segundo esse antropólogo, tomar a questão da nacionalidade no continente africano pela via da análise do estado nacional é improdutiva, porque "as formas de institucionalização da autoridade não se reduzem ao modelo europeu do estado nacional” (Trajano Filho 1993, 7).

Em outra ocasião, o autor esclarece que "a nação é uma comunidade de sentimento que se cristaliza em projetos de diferentes matizes e estilos de competição na arena política" (Trajano Filho 2016, 915). Esses projetos podem ser elaborados por via institucional (Estado, partidos políticos, movimentos sociais etc.) ou "ter uma autoria difusa e ganhar expressão pública nos rumores disseminados de modo apaixonado e dramatizado nas rodas de conversa, nas estórias exemplares e em outras formas narrativas tradicionais” (Idem). Para os objetivos deste artigo, entretanto, concentro-me na via institucional.

Não cabe aqui esmiuçar o projeto de nação em Moçambique conduzido pelo governo da Frelimo entre 1975 e 1980, tendo em vista que o foco do texto é outro. Ressalto, entretanto, que ele se pautou na edificação de uma comunidade nacional onde todos seus habitantes - cerca de 13 milhões de pessoas espalhadas pelo território, falantes de línguas diversas, pertencentes a contextos sociais específicos - deveriam assumir uma identidade única, o ser moçambicano. Essa coletividade teria em comum a submissão a Portugal e a união na história recente para expulsar o colonizador (um passado comum, como aparece em vários discursos oficiais). A Frelimo personificou essa unidade histórica, de caráter essencialmente
6 Denominação atribuída aos praticantes da música e dança das timbila. 
nacionalista, e a instituiu na construção de um estado soberano (Geffray 1988).

Esse projeto de nação e sua ambição em relação ao desenvolvimento da sociedade moçambicana se amparou na idealização do "homem novo", nascido da ruptura com antigos valores advindos da sociedade colonizada, da sociedade burguesa e da sociedade "feudal" (Tempo, 21 de maio de 1978, 27-37). O homem novo foi imaginado como alguém que rejeitaria de forma consciente as heranças coloniais (especialmente o tribalismo e o obscurantismo) em prol da construção de uma nova sociedade, presumivelmente mais justa. Essa categoria foi a alternativa encontrada face às categorias coloniais rechaçadas, a exemplo de indígenas e assimilados (Farré 2015, Macagno 2009).

O processo da transformação dos sujeitos em homens novos teria tido início na luta armada pela independência, período em que seriam socializados como novos cidadãos (Farré 2015, Cabaço 2009, Macagno, 2009). A luta de libertação foi concebida também como uma luta pela libertação cultural, de inculcação de novos valores; a música com conteúdo revolucionário teve um papel fundamental na mobilização dos combatentes (Siliya 1996). A criação do homem novo estender-se-ia, portanto, para a luta pela criação do Povo moçambicano no interior de uma nação unitária e uniforme, a qual deveria "eclipsar toda tentativa particularista, localista e tribalista" (Macagno 2009, 22). Do ponto de vista da "cultura", moçambicanos e moçambicanas seriam obrigados a abandonar quaisquer vinculações à herança cultural portuguesa de modo a serem educados para pertencerem ao Povo, processo que teria começado nas zonas libertadas e se espalhado para outros contextos da nova sociedade.

A grande frente de atuação da Frelimo para colocar esse projeto em ação se efetuou no meio rural com a implantação das aldeias comunais (Cahen 1987, Geffray 1998). Em relação às expressões artísticas, "a cultura era entendida como uma arma de educação revolucionária e como um instrumento de criação de um homem novo e de uma sociedade nova" (Costa 2013, 256). Práticas associadas à produção artística não foram classificadas como reacionárias, sendo inclusive valorizadas, pois estimulariam a capacidade criativa na transformação para o homem novo (Cabaço 2009).

Nesse sentido, o palco teve um papel simbólico decisivo, pois representava o lugar concedido ao "Povo" pela Frelimo, um lugar de destaque na nação que estava em vias de construção. $O$ palco era o espaço idealizado pelo partido único que governava o país para a exibição das manifestações desse Povo, tal como concebido no seu projeto de unidade nacional. Este espaço coletivo se opunha a uma outra coletividade, que a Frelimo queria erradicar: aquela associada às práticas consideradas tribalistas. O mato era entendido como locus do atraso, do obscurantismo, da antirrevolução. A proposta era, então, levar “o Povo”, representante legítimo da verdadeira e autêntica cultura do país, para a ribalta. Assim, livre das ligações tribais, ele passaria a desenvolver sua "arte" em prol da revolução e do processo de modernização do país. O palco foi concebido como a redenção dos "desvios" que se produziam no mato, um local privilegiado para o surgimento do homem novo.

Antes de avançar para a discussão central do artigo, justifico minha escolha 
pelo título e pelo modo como estou utilizando esses dois termos. Palco e mato são categorias de entendimento por meio das quais meus interlocutores, praticantes de timbila, ${ }^{7}$ concebem, ordenam e classificam suas experiências de vida e suas práticas musicais. Assim, o palco e o mato não designam simplesmente espaços físicos, mas sobretudo domínios culturais institucionalizados que instauram modos de exibição, padrões de interação e relacionamentos sociais. Quando conversava com meus interlocutores nas localidades rurais em Zavala (distrito localizado na província de Inhambane), nas vilas e nas cidades, essas palavras eram mencionadas para exprimir algo além do que o espaço em que os grupos de timbila se apresentavam. E assim se expressavam também outros praticantes do que se convencionou chamar naquele país de dança ou música tradicionais.

Por mato, tal como indicam os timbileiros, me refiro aos interiores rurais dos distritos moçambicanos, locais onde residem tocadores e dançarinos e onde as timbila e outras expressões se manifestam com intensa vivacidade por meio de "cerimônias tradicionais", casamentos e outras festividades constituidoras da sociabilidade dos diversos grupos sociais existentes no território moçambicano. Já o palco designa, em geral, um suporte de madeira ou cimento, elevado ou não do chão, utilizado principalmente para exibições em festivais; são espaços que delimitam as fronteiras entre artistas e audiência, onde a música é vivenciada como um domínio exclusivo da experiência. Enquanto no mato as timbila e outras expressões musicais se relacionam mais proximamente com formas de interação social características dos eventos mencionados acima, nos quais, em geral, todos os presentes se conhecem previamente e compartilham laços de parentesco, amizade e/ou vizinhança, no palco as timbila se apresentam perante uma audiência mais diversa e indiferenciada durante um período de tempo estrito. $O$ palco é o local do espetáculo por excelência, onde os músicos gostam de dar o melhor de si para agradar ao público e para competir pela melhor performance com outros grupos.

O mato, entretanto, pode também ser visto como palco em certas ocasiões, o que indica a intensa complementariedade entre essas duas categorias, além da própria fluidez de ambas no tocante à localização geográfica. Creio ser mais produtivo, nesse sentido, apreendê-los como zonas de relacionamento social, tal como propõe Kopytoff (1977); ou ainda, na perspectiva de Trajano Filho (2010, 246), como "um espaço conceitual de atuação de uma rede de sociabilidade geradora de sentimentos de pertencimento". Ao mobilizar essas duas categorias neste texto, pretendo enfatizar como, no contexto abordado, tais dimensões da vida social foram tratadas como apartadas uma da outra. Se as expressões musicais denominadas tradicionais eram vistas como originárias dos matos e a eles restritas, restava ao palco sua redenção, sua transformação como música fim destinada a uma audiência diferenciada, assim como a transformação de seus executantes em homens novos em uma sociedade nova. Essa estratégia dificilmente encontrou respaldo nas complexas realidades e dinâmicas dos vários grupos sociais da sociedade moçambicana.

A violenta guerra civil que se desenrolou de 1976/1977 a 1992 comprometeu
7 Conforme descritas pela bibliografia especializada, timbila são instrumentos musicais do tipo xilofone, tocadas em grandes agrupamentos por populações chopes de Moçambique (Tracey, 1948; Rita-Ferreira, 1975; Dias, 1986; Munguambe, 2000; Jopela, 2006; Webster, 2009; Wane, 2010). Mais amplamente, o termo timbila designa, a um só tempo, dança, música, instrumento e poesia. A forma singular de timbila é mbila. Em geral a utilização da forma escrita mbila se refere a um único instrumento, e timbila ao agrupamento mais amplo de instrumentos. Atualmente, grupos de timbila são entidades autônomas, fundadas e chefiadas por timbileiros que habitam o distrito de Zavala em localidades rurais espalhadas por vários pontos daquele território. Sua configuração tende a ser fluida (principalmente para o caso dos dançarinos), havendo uma substituição constante dos membros de um agrupamento em razão da acentuada movimentação de pessoas onde vivem os timbileiros. Reúnem-se periodicamente para ensaiar seu repertório e para se apresentarem em cerimônias e eventos diversos. 
esse projeto de nação proposto pela Frelimo. Uma guerra de guerrilhas, conduzida contra a Renamo (Resistência Nacional Moçambicana) - que construiu sua base social a partir de grupos rurais em todo o país - colocou a Frelimo numa situação extrema. Segundo Geffray (1991, 15), os dirigentes que conceberam o novo Estado soberano foram "incapazes de pensar a construção da nação sem apagar ao mesmo tempo a diversidade e a heterogeneidade concretas e históricas dos grupos sociais que pretendiam unir e integrar sob o signo de uma identidade única”.

$\mathrm{O}$ artigo se divide em duas seções, além das considerações finais. Na primeira, descrevo em detalhes a programação do Festival Nacional da Canção e Música Tradicional (1980-1981), mostrando alguns momentos do evento, tais como apresentados pela mídia escrita e filmográfica da época. Na segunda seção, disponho de um debate promovido pelo Jornal Notícias durante e após o festival para compreender o modo como certos agentes do campo musical e cultural se manifestaram frente às apresentações nos palcos da capital do país. Finalmente, nas considerações finais, reforço o argumento do artigo ao discutir o papel ocupado pelos festivais culturais no projeto de construção da nação em Moçambique ainda hoje.

\section{O Festival de Canção e Música Tradicional: uma ofensiva cultural}

A apresentação dos diversos grupos selecionados para subirem ao palco do grandioso Festival da Canção e Música Tradicional foi utilizada pelo presidente Samora Machel e seus companheiros como metáfora do que deveria ocorrer para a constituição da nação moçambicana. Nas palavras da Ministra da Educação e Cultura, Graça Machel, quando entrevistada para o filme Música, Moçambique!, sobre o I FNCMT,

O Festival de Música e Canção Tradicional que nós realizamos enquadra-se no esforço do nosso Partido para a valorização da nossa própria identidade, da nossa personalidade moçambicana, e também para fazer com que as experiências individuais se tornem experiências coletivas, da comunidade; as experiências regionais, as manifestações culturais regionais se tornem manifestações culturais da nação moçambicana e, por isso mesmo, consolidar a unidade nacional.

Também um esforço de levantamento e registro daquilo que é uma grande diversidade e constitui, por isso mesmo, uma grande riqueza da nossa cultura, de modo a que, de uma forma sistematizada e organizada, nós possamos valorizar que existe de mais genuíno em nós.

Nós temos raízes comuns, um passado comum, uma história e uma cultura que nos é comum. [...] De facto, as fronteiras não têm qualquer significado. Os povos estão unidos pelos mesmos valores, os povos estão unidos pelos mesmos objetivos, e como povos somos humanidade, e como humanidade temos deveres, temos valores, temos uma cultura que nos é comum, temos responsabilidades que nos são comuns no nosso século, e andamos de mãos dadas. 
O pronunciamento da Ministra está repleto de elementos que constituíam o discurso clássico da Frelimo. Ele apresenta o grande dilema da construção da nação: consolidar a unidade nacional a partir das diferentes manifestações culturais presentes no território. Essa unidade estava assente num projeto nacionalista de poder que negava as especificidades e as heterogeneidades históricas dos processos de formação dos povos do território. Tal negação se coadunava à invenção de um país imaginário e fictício onde uma aliança de trabalhadores e camponeses teria delegado sua autoridade à Frelimo para que ela a exercesse em seu nome diante dos seus inimigos (Geffray 1988, 69). A organização aventada no discurso da ministra, tratada como essencial para a valorização da cultura, desconsidera que os grupos pertencentes ao território moçambicano já possuíam suas próprias formas de organização; como aponta Geffray, tratava-se da ideologia da "página em branco" (Idem, 65). ${ }^{8}$

Antes de partirem rumo a Maputo, os grupos que se apresentariam naquele grandioso evento foram selecionados por pessoas ligadas ao Gabinete Central de Organização do Festival. Os dados a que tive acesso indicam que foram organizados "mini festivais", nos quais participaram as principais expressões musicais de cada província. Os critérios de participação, avaliação, assim como de definição do que poderia ser classificado como música tradicional não estavam explícitos no material levantado no Arquivo Histórico de Moçambique e no Arpac (Instituto de Investigação Sociocultural), mas algumas informações sobre esses momentos pré-Festival foram encontradas:

Nas fases já realizadas, puderam participar todas as pessoas que mostraram capacidade para cultivar actividades musicais no campo tradicional e que para tal se inscreveram. A única limitação posta, foi a de não se exibirem instrumentos e música que fugissem às características tradicionais (música ligeira, clássica, etc).

A competição teve a presença e o apoio populares, com a classificação a cargo de júris que se basearam em critérios essenciais: a música (ritmo, melodia, harmonia, acompanhamento, significado e alcance social ou cultural do texto - letra); interpretação, afinação de vozes; decoração dos instrumentos; originalidade dos trajes. Houve a preocupação de não impor estes critérios rigorosamente, admitindo-se a flexibilidade necessária para garantir a espontaneidade criadora dos artistas.

$[\ldots]$

No Niassa, competiram 130 artistas (com uma previsão de 120), distribuídos por 21 conjuntos vocais e instrumentais e 15 solistas, apurando-se um conjunto e um artista individual por distrito, excepto de Lichinga [...]; Na Zambézia, participaram 139 artistas, sendo 8 individuais e 131 em conjuntos, com grande apoio popular e destacando-se alguns artistas de elevado mérito de interpretação;

Em Gaza, de mais de 2100 cantores e instrumentistas da fase distrital, estiveram na fase provincial 185, com 18 instrumentos e mais de 30 canções
8 A noção de organização de pessoas no projeto ideológico de construção nacional nos primeiros anos pós-independência é fundamental para se compreender o modo como a Frelimo se relacionava com seus governados. Para uma discussão sobre o tema concentrada nas aldeias comunais, ver Cahen (1987) e Geffray (1988). Importante também no período imediatamente pós-independência foi o estabelecimento dos Grupos Dinamizadores, comitês de participação em massa mantidos em locais de trabalho e áreas residenciais responsáveis por "organizar" a população em torno das decisões políticas e angariar apoio para elas, assim como controlar movimentos de pessoas em ambientes urbanos. Os GDs começaram a desaparecer ainda em 1978 e foram substituídos por estruturas sindicais, células partidárias e chefes de quarteirão (Darch, 2018). A "organização" de pessoas para se apresentarem em festivais de cultura, observada no contexto descrito neste artigo, tem ressonância ainda hoje nesses eventos, os quais contam com forte presença de autoridades políticas. Desenvolverei esse assunto em trabalhos futuros. 
Uma matéria do Jornal Notícias explica que, em alguns casos, bons artistas foram eliminados porque "apresentaram instrumentos não considerados tradicionais, mas que constituem parte dos mais populares, em algumas regiões do nosso País. Tal foi o caso que aconteceu na província da Zambézia em que um tocador de acordeão foi afastado nas competições provinciais" (Notícias, 30 de novembro de 1980, 1). Outros membros desse mesmo Gabinete viajaram para todas as províncias do país num momento posterior para atuarem na produção artística (vestimentas, coreografias, posicionamento no palco, tempo de apresentação etc.). Essa segunda etapa ocorreu na primeira quinzena do mês de dezembro de 1980 quando, no dia 8, os representantes do governo viajaram para as capitais de cada província e retornaram com os grupos a Maputo no dia 22 de dezembro. Na capital do país, algumas pessoas ligadas à organização do evento preocupavam-se com os espaços de alojamento e alimentação dos artistas, enquanto outros arrumavam os espaços de apresentação dos grupos (Praça de Toiros, para a abertura, e Pavilhão do Maxaquene, para as atuações gerais e a cerimônia de encerramento).

A fase final, ou seja, o Festival propriamente dito, contou com cinco apresentações no Maxaquene, duas províncias por dia: cada uma delas tinha direito a 45 minutos de exibição, sendo cada grupo composto por cerca de 40 “artistas”. Além do Presidente da República, Samora Machel, muitos dos seus ministros de Estado, membros do partido Frelimo, cooperantes e representantes do corpo diplomático foram convidados oficialmente. Estiveram presentes autoridades políticas dos seguintes países: Zimbabwe, Tanzania, Angola, Lesotho, Suazilândia, Argélia e Zâmbia. A abertura realizou-se na Praça de Toiros, dia 27 de dezembro às 16h, e foi a única programação gratuita do evento, incluindo o transporte "das massas das zonas mais distantes como é o caso dos bairros da Matola, T-3 e Benfica e dos trabalhadores que, organizados e integrados nas estruturas dos Conselhos de Produção, deverão começar a concentrar-se na 'Monumental”, a partir das 14 horas” (Notícias, 27 de dezembro de 1980, 1).

O presidente Samora Machel, que foi recepcionado no local pelo som do hino nacional, interpretado pela Banda das Forças Armadas de Moçambique, abriu o evento saudando os representantes das dez províncias do país, e sublinhando que "através da dança e dos músicos eles mostram o nosso passado, segredo da força que quebrou as algemas, o tribalismo, o regionalismo e o racismo, e mostram o internacionalismo, a solidariedade e, sobretudo, a unidade do Povo moçambicano" (Notícias, 28 de dezembro de 1980, 1). Outros hinos foram executados enquanto desfilavam na arena diversas crianças de escolas primárias e secundárias de Maputo, vestidas com roupas vermelhas, amarelas, verdes, azuis, pretas e brancas (alusão à bandeira no país), empunhando e agitando pequenas bandeiras com essas mesmas cores. Em seguida, entraram as dez delegações provinciais, "cada uma das quais empunhava uma tabuleta com nome da província representada e interpretando números culturais da sua zona de origem" (Notícias, 28 de dezembro de 1980, 11). 
Graça Machel, ministra da Educação e Cultura e Presidente da Comissão Nacional do Festival, em seu discurso nessa sessão de abertura, sublinhou que a realização do evento integrava as atividades da Campanha Nacional de Preservação e Valorização Cultural e afirmou, entre outras coisas, que

Este festival é mais uma manifestação da pujança criadora do povo moçambicano, este povo trabalhador que mostra aqui, à sua frente, senhor presidente, uma parcela da sua cultura, uma ínfima amostra do rico patrimônio de que é detentor. Em nome do governo da República Popular de Moçambique, declaro solenemente aberta a fase final do I Festival Nacional da Canção e Música Tradicional. A luta continua! (Trecho do filme Música, Moçambique!). ${ }^{9}$

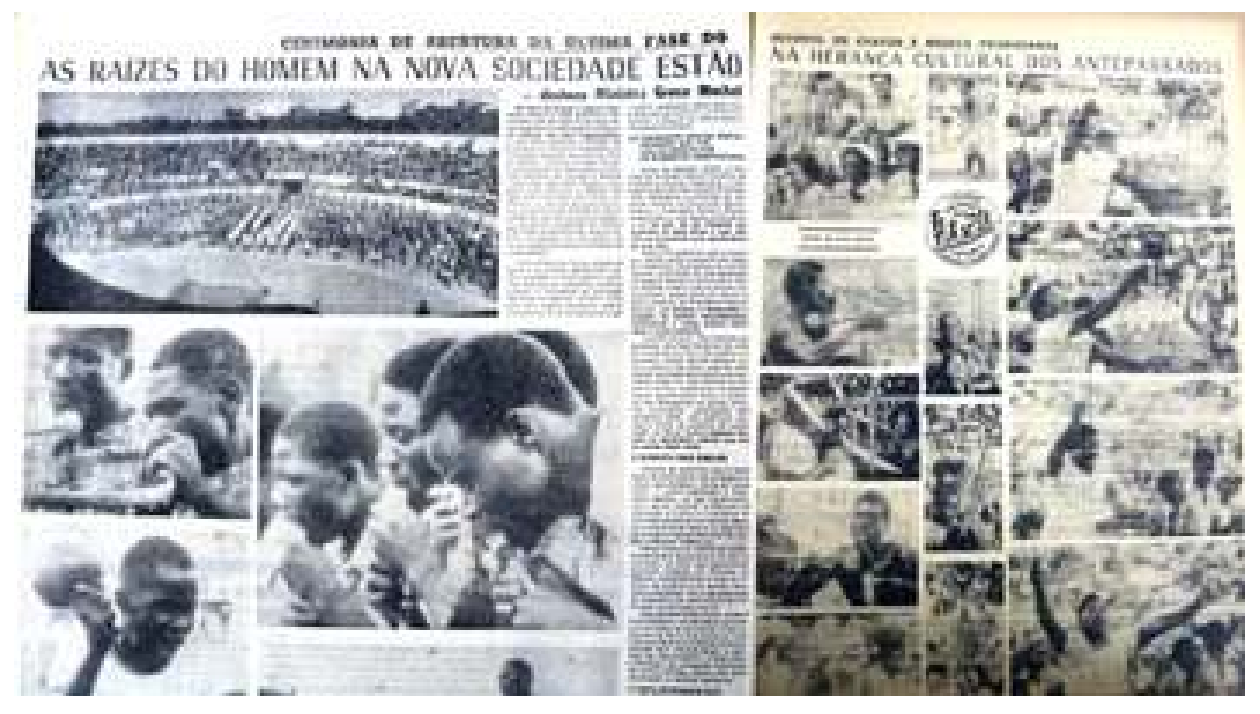

No primeiro dia das apresentações, 28 de dezembro, subiram ao palco circular do Maxaquene grupos de Maputo e de Nampula. Esta última foi representada pela dança nsope. Da província de Maputo, apresentaram-se um tocador de chizambe, alguns tocadores de timbila e a dança mutin. A respeito das timbila, matéria do Notícias comenta:

As timbilas, ainda que tocadas razoavelmente, perderam muito da sua importância, ao notarmos dentro do Festival a presença da Província de Inhambane que traz consigo os melhores tocadores, dentre os melhores que temos em Moçambique. Como sabemos, é na região de Zavala que este género instrumental tem maior fluência e significado (Notícias, 31 de dezembro de 1980, 2).

Incômodos como esse - uma província ser representada por uma expressão pertencente "genuinamente" a outra - foram apontados também em outros casos, como as nyangas; entretanto, o exemplo das timbila parece ser sempre o mais reiterado. ${ }^{10}$
9 O filme é uma coprodução Moçambique-Portugal para a Direção Nacional da Cultura de Moçambique; subsidiado pela Fundação Calouste Gulbenkian e pelo Instituto Português de Cinema; produzido por FILMFORM (Lisboa) e INC/Instituto Nacional do Cinema (Maputo) em 1981. Está disponibilizado na página do Arpac (Instituto de Investigação Sociocultural) no Facebook.

FIGURA 2 (à esquerda): Notícias, 28 de dezembro de 1980, p. 4.

FIGURA 3 (à direita): Notícias, 28 de dezembro de 1980, p. 5.

10 Esse aspecto do "certificado de origem" das expressões culturais possui, ainda hoje, um forte apelo no contexto de festivais nacionais. 
No dia 29 de dezembro, o segundo do Festival, apresentaram-se os grupos das províncias de Cabo Delgado, com os tambores do mapico, tocadores individuais de bangwè, kanyembe e dimbila; e Tete, com as flautas da dança nyanga e o mpalassa (conjunto de chifres). Os grupos das províncias de Sofala e Gaza tiveram sua vez no palco principal do evento no terceiro dia. Os artistas de Sofala expuseram os sons de 16 diferentes instrumentos, como o do tambor ntukula, e o duo de chibedebede. A participação dessa província foi elogiada pelo Notícias, pois os grupos teriam se organizado bem no palco e estavam muito animados, contagiando os músicos de outras províncias que assistiam, assim como a audiência na arquibancada. A apresentação dos corais dessa província foi também ressaltada.

No primeiro dia do ano de 1981 subiram ao palco representantes das províncias de Niassa e Manica. Fechou a noite o conjunto "Dumbi and the Maraire Marimba Ensemble”, do Zimbabwe, composto por músicos norte-americanos e zimbabweanos. Niassa executou "um raro instrumento de sopro com notada influência árabe que se poderia chamar ocidentalmente de um "trompete tradicional"' (Notícias, 4 de janeiro de 1981, 2). A atração principal dessa província teria sido um grupo de crianças composto por um banjo de três cordas, dois mpundus e uma clave confeccionada com lâminas de enxada. Manica levou um grupo coral de mulheres, varimba e um grupo de nyangas.

Dois de janeiro de 1981 foi dedicado às províncias da Zambézia e de Inhambane. A primeira apresentou um grupo de nove flautistas da dança nyanga e um coral de mulheres acompanhado com claves de madeira na percussão. Os redatores da matéria do Notícias lamentaram que a província não pôde levar representantes da dança cedo, "que representa neste género algo do mesmo peso e força que a timbila de Inhambane" (5 de janeiro de 1981, 3). Inhambane, por seu turno, mostrou: um coro tradicional estilo pergunta-resposta, um solista de chipendane e, claro, timbila. $\mathrm{O}$ espetáculo desse penúltimo dia de Festival teve a apresentação de Miriam Makeba e banda. ${ }^{11}$

O Festival terminou dia 3 de janeiro, quando ocorreu sua cerimônia de encerramento. Reportagem do Notícias explorou a expectativa gerada com a realização do fechamento oficial do evento:

O espectáculo, que vai atrair um numeroso público, representará a súmula de todo um trabalho desenvolvido no sentido de divulgar, valorizar e engrandecer o património cultural tradicional do Povo moçambicano. Ele será um marco histórico a registar nos anais da história do nosso Povo, no conjunto dos esforços desenvolvidos pelo nosso Governo, à luz das directivas do $3^{\circ}$ Congresso do Partido FRELIMO sobre a importância da preservação cultural (Notícias, 3 de janeiro de 1981, 1).

Exceto pelas críticas a respeito de certos aspectos da sua organização contidas nas "Crônicas do Festival", como abordarei posteriormente, o evento foi considerado um grande sucesso pela mídia. Diante da presença de Samora Machel, integrantes da Frelimo e convidados oficiais de outros países africanos, os artistas
11 No filme Música, Moçambique!, a cantora e ativista sul-africana aparece cantando a música "A Luta Continua". 
adentraram a arena do Maxaquene, bem-organizados, mas exultantes, segurando as placas onde se viam o nome da província correspondente a cada delegação presente, e seguiram em direção ao palco principal do pavilhão. A Banda das Forças Policiais executou o Hino Nacional. Na sequência, os "agrupamentos artísticos internacionais" se apresentaram, sendo "vibrantemente aclamados pela vasta assistência” (Notícias, 4 de janeiro de 1981, 1). Passou-se, então, à entrega de prêmios a todos os grupos das dez províncias, que consistiram em estatuetas em marfim. ${ }^{12}$ Os artistas internacionais foram agraciados com esculturas esculpidas em pau preto.

\section{Crônicas sobre o Festival: música tradicional em debate}

Após a realização do Festival, Martinho Lutero ${ }^{13}$ e Abel Esmael $^{14}$ produziram $^{-1}$ uma série de artigos com conteúdo crítico, cujo teor recaía fundamentalmente em aspectos da organização do evento. Esses escritos foram apelidados por seus críticos de "crónicas do festival” e geraram respostas de leitores, promovendo um acalorado debate no Jornal Notícias. ${ }^{15}$ No primeiro artigo por mim selecionado, os autores comentam sobre a falta de tambores no Festival. Citam a performance do “conguista” nas apresentações de Miriam Makeba, convidada de honra do evento, que entusiasmou o público. Lastimaram a falta de "membranófonos percutidos" dentre os instrumentos levados a Maputo pelos grupos selecionados e deram como exemplo a não inclusão, entre os instrumentos dos grupos da província da Zambézia, da "bateria de tambores da dança Cedo que representa neste género algo do mesmo peso e força que a timbila de Inhambane”. Criticaram a organização do Festival por não terem critérios para selecionar as expressões mais representativas e tradicionais de cada província. ${ }^{16}$

Em "Vamos reflectir e analisar sobre a nossa realidade cultural", Lutero e Esmael enfrentam a questão do estatuto dos termos canção e música. Perguntam a razão de as duas palavras serem enfatizadas no título: "talvez para diferenciar música cantada da tocada. Ora, se a questão era de purismo tal, dever-se-ia dar um adjectivo à música no título. Afinal, canção também é música”. Argumentam que não se trata apenas de uma questão formal, pois a dualidade contida no título representa a falta de rigor na organização e execução de todo o Festival. Aliada ao problema da divisão música $x$ canção estaria a separação impossível, aos olhos dos autores, da música em relação à dança, "indivisível no Continente Africano e consequentemente no nosso País. Quem não percebe o absurdo de desligar a dança da música, não perceberá o de desligar a canção da música”. Mostrando alguns exemplos do contexto abordado, Lutero e Esmael concluem que essa dissociação (tanto em relação à dança como em relação à canção) produz um mecanismo de redução da música, o que demonstra um "alheamento da realidade cultural moçambicana” por parte daqueles que conceberam o evento.

Ao dar o exemplo da música nsope, esclarecem:

Esta música tradicional tem como base o acompanhamento da dança, não possuindo moto-próprio como ideia, comunicação, mensagem e carácter
12 "Nos actos de entrega participaram todos os dirigentes do Partido e do Estado que na mesa do 'presidium' ladeavam o dirigente máximo da Revolução moçambicana" (Notícias, 4 de janeiro de 1981, 1).

13 Maestro brasileiro, atuou como cooperante no país a partir de 1978 na área da música. Foi um dos fundadores da Escola de Música de Moçambique, realizou algumas das investigações que auxiliaram a escolha dos grupos que se apresentaram no Festival.

14 Jornalista moçambicano. 15 Aparentemente, o Jornal Notícias teria incentivado o debate, mas não tenho informações sobre o possível convite dos editores da seção para que determinados leitores respondessem diretamente aos autores dos artigos.

16 "Qual será desta vez a justificação? A mesma de sempre, de que não há possibilidade de trazer muitos elementos de cada província? Então perguntamos: Por que trazer como representante da Zambézia um grupo de nove flautistas da dança "Nyanga", se essa dança não é tradicional daquela província? Seria o mesmo que num Festival Internacional de música ligeira levarmos como representante de Moçambique um grupo tocando "Jazz". Nós sabemos que no nosso País há grupos que fazem este tipo de música, mas não mandaríamos jamais um grupo de "Jazz" representar a música ligeira moçambicana. Enfim, coroou-se com éxito a falta de critério por parte da organização neste Festival" (Notícias, 5 de janeiro de 1981, 3). 
de obra musical. Não é por assim dizer, substantiva. Ela existe como se refere, ligada à dança, ou vice-versa, a dança ligada a ela.

A música em Moçambique, em África, tem um carácter utilitário. Como vemos, não é só uma questão de pureza conceitual, que por si só justificaria o protesto. É uma questão de pureza e respeito artístico. (Notícias, 11 de janeiro de 1981, 2)

Em "Uma importante contribuição política para consolidar a unidade nacional", terceiro da série, Lutero e Esmael se afastam do tom adotado em escritos anteriores para se dedicarem a um elogio ao caráter político do Festival. Afirmam, nesse sentido, que a realização do evento, além de ser valorizada em termos artísticos, deveria também, e principalmente, ser enaltecida em termos políticos. A explicação resume-se ao seguinte: ao possibilitar o encontro entre músicos das diversas etnias do país, o evento teria gerado uma conjuntura favorável à tomada de consciência de cada um desses sujeitos na direção de um pertencimento nacional. Ou seja, entendendo-se como parte de um todo, cada músico presente no Festival abdicaria da sua "identidade étnica" para se associar a uma coletividade mais ampla, motivo que os levaria a se sentirem "moçambicanos":

O músico chope encontrou o músico macua e o músico chissena, tocando, por exemplo, o Chipendane e as suas variações. De repente ele percebe que os três "povos" compartilham do mesmo instrumento de comunicação com a sua aldeia, portanto, têm algo de fundo em comum. Aos poucos dão-se conta enquanto tocam, que ali não está o macua, está o moçambicano. E assim a música tornou-se para eles um elemento de unidade (Notícias, 12 de janeiro de 1981, 2).

Essa espécie de "teoria do ponto crítico", que tenta explicar o nascimento da cultura nacional por meio do Festival, apoia-se, ainda, no argumento que reforça o encontro desses sujeitos de diferentes províncias e identificados por diferentes línguas: a ideia de que, pelo fato de terem todos vivido a opressão do colonizador, "têm uma identificação natural. [...] libertaram-se pelo mesmo processo, pela mesma guerra, e no momento de cantar a liberdade, o motor da criação artística era o mesmo" (Notícias, 12 de janeiro de 1981, 2). Assim, a unidade da nação, tão repetidamente evocada pela Frelimo em suas reuniões e em documentos oficiais, passou a ter sua existência chancelada por especialistas e entusiastas das artes musicais em Moçambique, o que certamente colaborou para a perpetuação desse imaginário e na própria concepção dos festivais futuros. Além disso, essa unidade é vivida ritualmente pelos próprios músicos e sua audiência, acrescentando algo de intensidade à experiência.

A primeira resposta às "crónicas" surgiu no dia 13 de janeiro de 1981, assinada por Arnaldo Bimbe. ${ }^{17}$ Antes de ponderar as críticas destinadas aos dois cronistas, Bimbe elogia o evento, ${ }^{18}$ para assim explicitar os seus desagrados, todos
17 No momento da minha pesquisa, Bimbe era chefe de gabinete do Ministro da Cultura e Turismo.

18 "Julgo que constituiu momentos inesquecíveis para os que puderam ter a oportunidade de se deslocar aos locais onde rufaram os tambores da nossa libertação". 
centrados nas assertivas sobre a falta de preparo por parte da organização do evento, tal como colocaram os dois autores em seus artigos. Finalizado o elogio, aponta a seguinte frase escrita por Lutero e Esmael como cerne das suas colocações críticas, considerando-a um insulto àqueles que se dedicaram aos preparativos do Festival: "Infelizes seres esses que se julgam com o direito de indicar ao artista popular a forma como deve tocar o seu instrumento..." (Notícias, 13 de janeiro de 1981, 2). Bimbe interpreta que, para as apresentações dos grupos em Maputo, houve um trabalho positivo de "preparação técnica dos artistas", que orientou os participantes sobre como deveriam se localizar no palco, quais seriam os momentos corretos para começar e terminar a tocar, quanto tempo teriam para tocar etc. Ou seja, ele considera que as orientações dadas àqueles que se apresentaram no Festival foi importante, tendo essa disciplinarização surtido efeito na exitosa execução dos músicos e, portanto, do próprio evento.

A réplica de Lutero e Esmael foi publicada um dia depois, por meio da qual seus autores explicaram que em nenhum momento foi intenção desmoralizar "as estruturas que tanto trabalharam para o sucesso do Festival". Rebate a afirmação tachada de insultuosa, afirmando que a frase não se referia aos aspectos mais gerais de coreografia, tempo determinado para tocar, entre outros, mas às "mutilações" feitas à música nyanga. Segundo Lutero e Esmael, o termo "forma" foi mal interpretado pelo leitor; refere-se à "forma de tocar”, à "forma musical”. Nesse sentido, somente o executor da música ("o real produtor da cultura") seria legitimado a indicar a forma correta.

Em 19 de janeiro de 1981 é publicado o texto de Calisto Mijigo, ${ }^{19}$ intitulado "A propósito das crónicas de Martinho Lutero e Abel Esmael”. O autor comenta sobre a importância da realização do Festival, que foi "um sucesso incontestável”. Afirma que todo o "Povo moçambicano" participou porque foi devidamente mobilizado pelo "Estado Socialista e o Governo", o que demonstra que o evento não foi apenas uma manifestação de natureza cultural, mas eminentemente política. Após expor a ideia de que Moçambique estaria vivenciando um progresso cultural necessário no processo de "evolução socialista", Mijigo confidencia que quando estavam planificando a concretização do Festival, surgiram algumas questões relativas à definição do seu título e dos seus objetivos. Segundo ele, algumas pessoas sugeriram o nome "Festival da Canção e Música", para que pudessem incluir o canto coral moderno e a música ligeira; outros eram contra a própria realização do evento, pois argumentavam que o "povo" ainda não estava "musicalmente educado a ponto de compreender o valor histórico deste acontecimento". Infelizmente não explica o ponto em que foi tomada a decisão pela inclusão da palavra tradicional nem o que motivou, afinal, a organização do Festival, apesar do problema colocado.

De acordo com Mijigo, Lutero agiu como tal no texto do jornal devido ao sistema político do seu país (no caso, o Brasil), "onde os problemas importantes que exigem uma solução diferente são tratados na imprensa à sorte do leitor” e, apesar de ter feito pesquisa e escrito sobre a música tradicional moçambicana, acabaria por defender a teoria dos musicólogos ocidentais ao afirmar que essa música só existe tendo como base o acompanhamento da dança. Fornece, no seu texto,
19 Músico, professor da Escola de Música em Maputo à época. 
exemplos de algumas situações nas quais é possível experimentar a música sem necessariamente dançar. Explica que, ao treinarem os "artistas" como deveriam se portar no palco, não estavam diminuindo a música tradicional, mas propondo uma "qualidade historicamente nova". Um "alheamento na arte", segundo Mijigo, seria, por exemplo, incluir na orquestra de timbila mais instrumentos que não fazem parte daquela formação (um acordeão, uma guitarra, uma trombeta), ou ainda incluir no M'saho "mais cinco movimentos do Samba". Após apontar esses assuntos mais relacionadas ao conteúdo das crônicas, Mijigo volta a questionar a idoneidade dos autores, acusando-os de "levantar uma campanha de desnortear a opinião pública nacional e internacional".

A longa resposta dos dois cronistas apareceu no Notícias dia 21 de janeiro do mesmo ano. Em primeiro lugar, defenderam-se afirmando que nunca se colocaram como donos das verdades sobre o tema da cultura em Moçambique, e muito menos como os maiores conhecedores da música tradicional do país. Afirmam que o objetivo da cooperação que realizavam era contribuir para o trabalho de recolha e valorização cultural, o que fizeram durante dois anos e meio (de 1978 a 1980) de pesquisas nas províncias de Maputo, Inhambane, Cabo Delgado, Nampula, Tete e Sofala. Criticaram a "pessoalização das questões" colocadas por Mijigo, "músico da Direcção Nacional de Cultura", e informaram que, diferentemente da afirmação de que um dos articulistas seria originário de um país onde problemas dessa natureza seriam tratados publicamente no jornal, a pessoa a quem se referia vivia "debaixo de uma ditadura militar que exactamente não permitia que tais problemas fossem abordados pela imprensa, totalmente controlada pela censura fascista" (Notícias, 21 de janeiro de 1981, 2).

Lutero e Esmael escreveram alguns parágrafos justificando o que entendiam por música tradicional e esclareceram que, quando afirmavam que a música em Moçambique estava ligada à dança, referiam-se a esse gênero de música. Elucidaram que, quando fizeram a afirmação da música como "moto-próprio sem ideia", aludiam especificamente ao nsope, visto que a melodia e a harmonia dessa música não foram criadas para serem apresentadas isoladamente, necessitando da dança e do poema cantado. Questionados a respeito da colocação sobre a ideia de utilitarismo associada à música tradicional, respondem que essa assertiva não diminui o valor nem a complexidade desta; ao contrário, "se somos músicos honestos, não podemos deixar de reconhecer o alto desenvolvimento técnico de expressões como Nyanga e Timbila". Após essas e outras respostas dos autores, as "crônicas do festival" não tiveram seguimento, tendo sido concentradas somente durante o evento e em momentos após o seu encerramento. Esse debate tornou-se relevante não somente pela discussão terminológica por parte de especialistas do campo musical e cultural da época, mas também por elucidar tensões internas a certas frentes de um projeto que se anunciava como uno e inquestionável.

\section{Considerações finais: festival, palco e nação}

A atenção despendida com a cultura nos primeiros anos pós-independência 
foi a fórmula encontrada pela Frelimo para somar as distintas expressões do povo que resultassem na nação moçambicana. Acessar músicas e danças praticadas por diferentes grupos sociais do território permitia que o governo se comunicasse com pessoas de todo o país. A construção da nação exigia um grande movimento de sensibilização dos habitantes de norte a sul para a causa maior que os deveria unir como um só povo, e o Festival Nacional da Canção e Música Tradicional foi o grande palco para apresentar esse projeto. Os temas relativos à independência e à luta contra o colonialismo, abordados através da linguagem da revolução socialista, eram reiteradamente evocados nos discursos dirigidos ao "povo moçambicano", totalidade esta bastante indefinida.

A ideia recorrente nessa época era de que a música moçambicana havia sido impedida pela "classe dominante" de ser difundida por outros espaços da sociedade. Pensava-se que, durante séculos, as práticas musicais relacionadas a cerimônias tradicionais (fúnebres, matrimonias, cantos de trabalho etc.) foram obrigadas pelo colonizador a ficarem restritas a esses eventos, sem relação com outras formas de comunicação com um público mais amplo.

Orlando Mendes, em artigo publicado pela Revista Tempo em 28 de dezembro de 1980, afirma que o colonizador teria reforçado a "autoridade tribal pela sua integração controlada na máquina administrativa", impedindo, assim, a "arte musical" de se desenvolver autonomamente, "sujeita ao peso de uma ideologia opressora, obscurantista e segregacionista". Segundo ele, os artistas teriam ficado por muito tempo fechados em seu mundo "obscurantista", o que explicaria o ocaso a que foram destinados muitos instrumentos musicais. A independência teria permitido que esses artistas saíssem da escuridão e se mostrassem a todo o país, processo este iniciado nas zonas libertadas. O Festival Nacional de Canção e Música Tradicional pode ser visto, nesse sentido, como um mostruário da "cultura popular", a ofensiva cultural de maior envergadura dentre todas as outras em que vinham sendo investidas.

A expressão "canção e música tradicionais" somente fazia sentido e foi foco de atenção do governo da Frelimo pelo potencial de arregimentação de pessoas com fins políticos que um evento como o Festival proporcionou. Evidentemente seu título não passa despercebido e reflete escolhas que não foram feitas ao acaso, para não citar a polissemia do termo. $O$ tradicional (entendido como autêntico, como vivido antes da colonização) não era uma ameaça à Frelimo, desde que não se virasse contra a modernização por ela reclamada, pois era entendido como condição historicamente inerente à formação do "povo moçambicano", o que inclusive possibilitaria sua transformação em direção ao homem novo. Passadas pelo crivo revolucionário, essas práticas estariam salvas; o problema era o tribal.

Não causa espanto que as respostas endereçadas aos dois cronistas, assinadas por pessoas diretamente envolvidas na concepção do Festival, não demonstraram nenhum descompasso entre o que se esperava que os artistas fizessem no palco e aquilo que traziam de seus contextos de origem. Nesse sentido, o elogio ao modo como os grupos atuaram é também um elogio ao exitoso trabalho que a Frelimo teria desenvolvido ao iniciar o processo de modernização das práticas culturais 
moçambicanas. No decorrer dos anos, os festivais passam a se alinhar cada vez mais com a denominação "cultural", e não mais com "tradicional" ou "popular", embora existam modalidades de "dança e música tradicionais" e palcos específicos para apresentações de expressões que nelas se encaixem (Morais, 2020).

O processo de modernização apregoado pela Frelimo no campo musical passaria, então, pela evolução de práticas de sociabilidade vividas no mato - seja no cotidiano ou em eventos extraordinários da vida coletiva - para apresentações públicas, as quais, dissociadas do contexto em que foram desenvolvidas (embora mantendo seu conteúdo), pudessem comunicar a plateias mais amplas e diversificadas sua capacidade de produção artística. No palco, os artistas se tornariam homens novos. $\mathrm{O}$ fracasso do projeto nacionalista dos primeiros anos evidenciou que essas dimensões da vida social não estão apartadas da dinâmica das práticas musicais e que seus praticantes se adaptam e se recriam nos mais diversos espaços a eles destinados, tanto no palco, quanto no mato.

Os festivais retornam à cena nacional nos anos 2000. O governo moçambicano, na área da cultura, voltou-se para a implementação de atividades que se adequassem às responsabilidades do Estado incluídas na legislação vigente após o fim da guerra civil, com a publicação da Política Cultural de $1997 .{ }^{20}$ A efervescência gerada por um grande festival nacional, atualmente realizado a cada dois anos, ${ }^{21}$ funciona para renovar periodicamente os sentidos de soberania nacional e serve também como vitrine de propaganda política da Frelimo. Nesse evento, a cultura (compreendida como patrimônio, como música, como arte, entre outros) é a linguagem comum que liga todos os grupos do território moçambicano, sendo um dos projetos mais eficazes de imaginação da cultura nacional. Já não se trata mais de utilizar o palco como fórmula para a correção dos "desvios" do mato, mas de construí-lo como mostra da diversidade cultural moçambicana, com ênfase em suas particularidades regionais. ${ }^{22}$

O Festival Nacional da Cultura é um ato político, uma das formas encontradas pelos governos da Frelimo para juntar pessoas em certo tipo especial de coletividade e exercer sua soberania. Nesse sentido, o palco segue desempenhando um papel fundamental no cenário político moçambicano. Se, no passado, como aponta Honwana $(2017,65)$, os festivais foram "a fórmula encontrada para fazer a afirmação cultural da identidade nacional", eles continuam tendo um lugar importante na linha de atuação dedicada à política cultural, especialmente no campo do patrimônio cultural, e mais recentemente têm sido concebidos sob a rubrica genérica das indústrias culturais e criativas. Há uma década esse grande evento bianual tem incorporado muitas das diretrizes assinaladas durante as reuniões da Primeira Conferência Nacional da Cultura em 1993, como, por exemplo, a busca pelos símbolos regionais e nacionais. Nos escombros de uma guerra civil que mal havia se encerrado, a realização dessa conferência parecia repactuar a construção da nação, porém em bases renovadas: ao invés do homem novo, o reconhecimento de uma sociedade "multicultural", "multiétnica" e diversa.

O Festival Nacional da Cultura não é somente um evento de cultura, de demonstração da diversidade cultural do país, de intercâmbio de experiências entre
20 Cf. BRM, Resolução $n^{\circ}$ 12/97, de 10 de junho de 1997. Aprova a Política Cultural e Estratégia de sua Implementação.

21 O último Festival Nacional da Cultura ocorreu em 2018, na província do Niassa, localizada no norte do país. Em 2020, devido à crise sanitária produzida pela pandemia de covid-19, o evento, que iria ocorrer em Maputo, foi cancelado.

22 É provável que a ênfase dada pelo governo da Frelimo no âmbito dos festivais nacionais à ancoragem regional/ geográfica das manifestações culturais, no lugar do seu pertencimento étnico, decorra de um possível temor em relação ao retorno insidioso do tribalismo ou de solidariedades étnicas. 
artistas das diversas partes do território nacional. Trata-se, sobretudo, de uma tecnologia de governo criada internamente - embora possa ter tido inspiração de experiências de outras partes do continente, como o I Festival de Artes Negras no Senegal, ou o Festac realizado na Nigéria - que vem sendo aprimorada desde o final da década de 1970. A fase final é apenas a ponta (uma ponta importante, certamente) de uma longa cadeia de eventos que produz efeitos muito particulares, como a relativa proximidade de pessoas moradoras do mundo rural com suas autoridades políticas oficiais e seu paulatino processo de alfabetização política e moral. Embora haja muito a ser explorado nesse debate, espero que o recorte temático aqui sugerido forneça uma via de análise promissora para o melhor entendimento sobre as formas assumidas pelo Estado em relação à população governada, assim como para desvelar possíveis projetos alternativos de construção nacional. 
Sara Morais

\section{Referências}

Anderson, Benedict. 2008. Comunidades Imaginadas. Reflexões sobre a origem e a difusão do nacionalismo. Trad. Denise Bottmann. São Paulo: Companhia das Letras.

Andrieu, Sarah. 2013. "Une forme globalisée, des enjeux localisés: Les festivals culturels régiounaux au Burkina Faso des années 1990 à aujourd'hui”. In Une histoire des festivals XX-XXI siècle, org. Anaïs Fléchet et al., 123-38. Paris: Publications de la Sorbonne.

Apter, Andrew. 2005. The Pan-African nation: oil and spectacle of culture in Nigeria. Chicago: The University of Chicago Press.

Apter, Andrew. 2016. "Beyond Negritude: Black Cultural Citizenship and the Arab Question in FESTAC'77". In The First World Festival of Negro Arts, Dakar 1966. Contexts and Legacies, org. David Murphy, 151-65. Liverpool: Liverpool University Press.

Cabaço, José Luís. 2009. Moçambique: identidade, colonialismo e libertação. São Paulo: Editora UNESP.

Cahen, Michel. 1987. Mozambique: la révolution implosée. Paris: Éditions L'Harmattan.

Costa, Alda. 2013. Arte em Moçambique: entre a construção da nação e o mundo sem fronteiras (1932-2004). Lisboa: Babel.

Darch, Colin. 2018. Historical dictionary of Mozambique. Series: Historical dictionaries of Africa. Lanham, Maryland: Rowman \& Littlefield.

De Jong, Ferdinand. 2016. "Cultural Festivals in Senegal: Archives of Tradition, Mediations of Modernity". In The First World Festival of Negro Arts, Dakar 1966. Contexts and Legacies, org. David Murphy, 166-79. Liverpool: Liverpool University Press.

Dias, Margot. 1986. Instrumentos musicais de Moçambique. Lisboa: Instituto de Investigação Científica Tropical/Centro de Antropologia Cultural e Social.

Farré, Albert. 2015. "Assimilados, régulos, Homens Novos, moçambicanos genuínos: a persistência da exclusão em Moçambique”. Anuário Antropológico 40(2): 199-229.

Geffray, Christian. 1988. "Fragments d'un discours du pouvoir (1975-1985): du bon usage d'une méconnaissance scientifique”. Politique Africaine 29: 71-85.

Geffray, Christian. 1991. A Causa das Armas: Antropologia da Guerra Contemporânea em Moçambique. Porto: Edições Afrontamento.

Honwana, Luís Bernardo. 2017. A velha casa de madeira e zinco. Maputo: Alcance Editores.

Isaacman, Allen and Isaacman, Barbara. 1983. From Colonialism to Revolution, 19001982. Boulder, Colorado: Westview Press.

Jopela, Valdemiro. 2006. "Para uma caracterização da poesia oral nas timbila dos Vacopi e alguns aspectos do contributo português 1940-2005”. Tese de doutorado, Universidade de Lisboa.

Kopytoff, Igor. 1977. "Matrilineality, residence, and residential zones". American Ethnologist 4: 539-58.

Kruks, Sonia. 1987. "From Nationalism to Marxism: the ideological history of Frelimo, 1962-1977". In Studies in Power and Class in Africa, ed. Irving Leonard Markovitz, 237-56. New York: Oxford University Press.

Macagno, Lorenzo. 2009. "Fragmentos de uma imaginação nacional”. Revista Brasileira de Ciências Sociais 24(70): 17-35. 
Sara Morais

Morais, Sara S. 2020. "O Palco e o Mato. O lugar das timbila no projeto de construção da nação em Moçambique”. Tese de doutorado, Universidade de Brasília.

Munguambe, Amândio Didi. 2000. A Música Chope. Maputo: Promédia.

Murphy, David. 2016. "Introduction. The Performance of Pan-Africanism: Staging the African Renaissance at the First World Festival of Negro Arts". In The First World Festival of Negro Arts, Dakar 1966. Contexts and Legacies, org. David Murphy, 1-42. Liverpool: Liverpool University Press.

Newitt, Malyn. 1995. A History of Mozambique. Bloomington and Indianapolis: Indiana University Press.

Rita-Ferreira, António. 1975. Povos de Moçambique: história e cultura. Porto: Afrontamento.

Siliya, Carlos Jorge. 1996. Ensaio sobre a cultura em Moçambique. Maputo: Publicita.

Trajano Filho, Wilson. 1993. Rumores: uma narrativa da nação. Série Antropologia 143: 2-35.

Trajano Filho, Wilson. 2010. "Território e idade: ancoradouros do pertencimento nas manjuandadis da Guiné-Bissau”. In Lugares, Pessoas e Grupos: as lógicas do pertencimento em perspectiva internacional, org. Wilson Trajano Filho, 225-55. Brasília: Athalaia.

Trajano Filho, Wilson. 2016. “O projeto nacional na Guiné-Bissau: uma avaliação”. Estudos Ibero-Americanos 42(3): 913-43.

Wane, Marílio. 2010. "A Timbila chopi: construção de identidade étnica e política da diversidade cultural em Moçambique (1934-2005)". Dissertação de mestrado, Universidade Federal da Bahia.

Webster, David J. 2009. A sociedade Chope: indivíduo e aliança no Sul de Moçambique, 1969-1976. Lisboa: ICS. 